\title{
THE
}

\section{Assessment of Food Intake, Obesity, and Health Risk Among the Homeless in Rhode Island}

Diane C. Martins

University of Rhode Island, dcmartins@uri.edu

Kathleen S. Gorman

University of Rhode Island, kgorman@uri.edu

Robin J. Miller

Leah Murphy

University of Rhode Island

Sekboppa Sor

Hoilivewsity of and add itslanal works at: https://digitalcommons.uri.edu/nursing_facpubs

The University of Rhode Island Faculty have made this article openly available.

Please let us know how Open Access to this research benefits you.

This is a pre-publication author manuscript of the final, published article.

Terms of Use

This article is made available under the terms and conditions applicable towards Open Access Policy Articles, as set forth in our Terms of Use.

\section{Citation/Publisher Attribution}

Martins, D. C., Gorman, K. S., Miller, R. J., Murphy, L. , Sor, S. , Martins, J. C. and Vecchiarelli, M. L. (2015), Assessment of Food Intake, Obesity, and Health Risk among the Homeless in Rhode Island. Public Health Nurs, 32: 453-461. doi:10.1111/phn.12180

Available at: http://onlinelibrary.wiley.com/doi/10.1111/phn.12180/abstract 
Authors

Diane C. Martins, Kathleen S. Gorman, Robin J. Miller, Leah Murphy, Sekboppa Sor, Jonah C. Martins, and Maria L. Vecchiarelli

This article is available at DigitalCommons@URI: https://digitalcommons.uri.edu/nursing_facpubs/5 
Assessment of Food Intake, Obesity, and Health Risk among the Homeless in Rhode Island 


\begin{abstract}
The objective of this study was to examine the relationship between the nutritional status, incidence of food insecurity and health risk among the homeless population in Rhode Island. This correlational study utilized a convenience sample of 319 homeless adults from Rhode Island's largest service agency for the homeless. At the time, participants were living on the streets, in shelters, or were using Health Care for the Homeless services. Information on use of services such as access to emergency foods, shelters, and the Supplemental Nutrition Assistance Program (SNAP) was requested. Food security was measured by the six-item subset of the USDA Food Security Core Module. Anthropometric measures included height, weight, and waist circumference. A 24-hour dietary recall was collected to determine the food intake for a subset of participants who agreed to supply this information $(n=197)$. Average dietary recall data indicated an insufficient intake of vegetables, fruit, dairy, and meats/beans. It also indicated an excessive intake of fats. Of the 319 participants, $29 \%$ were overweight and $39 \%$ were obese. Over $94 \%$ of the participants were food insecure, with $64 \%$ of this subset experiencing hunger. Fifty-five percent of the participants were currently receiving SNAP benefits. The majority of the sample was found to be food insecure with hunger.
\end{abstract}

Keywords: food security, nutrition, homelessness, Supplemental Nutrition Assistance Program. 
Assessment of Food Intake, Obesity, and Health Risk among the

Homeless in Rhode Island

Over three and a half million people are likely to experience homelessness within a given year (National Coalition for the Homeless, 2009). Homelessness, according to the McKinneyVento Homeless Assistance Act, is defined as lacking a fixed, regular, and adequate night-time residence or having a primary night time residence that is (a) a supervised publicly or privately operated shelter; (b) an institution that provides a temporary residence for individuals intended to be institutionalized; or (c) a public or private place not designed for regular sleeping accommodation for human beings (The McKinney-Vento Homeless Assistance Act, 1987). The problem is further complicated when shelter is not available. The U.S. Conference of Mayors Annual Survey on Hunger and Homelessness (United States Conference of Mayors, 2011) reported that $70 \%$ of cities surveyed indicated their emergency shelters must turn away unaccompanied individuals experiencing homelessness because beds are not available for them. Of the cities surveyed, $66 \%$ reported that shelters must turn away homeless families with children for the same reason. Officials in $62 \%$ of the cities surveyed were able to estimate that $18 \%$ of the overall demand for emergency shelter went unmet during the past year.

In addition to the dire need for shelter, homeless individuals face greater health risks and die at a younger age compared to the general American population (Cheung \& Hwang, 2004; Turnbull, Muckle, \& Masters, 2007). Given the high prevalence of illness among homeless people and the adverse health effects of homelessness itself, it is not surprising that individuals facing homelessness have very high mortality rates. Specifically, men using homeless shelters were 2 to 8 times more likely to die from both chronic and acute illness than age-matched men in the general population (Hwang, Wilkins, Tjepkema, O’Campo, \& Dunn, 2009). Furthermore, 
individuals who are homeless are three to six times more likely to become ill than housed people. The homeless experience higher rates of both chronic and acute illness as compared to the general population (Schanzer, Dominguez, Shrout, \& Caton, 2007). In a nationwide survey of homeless adults, diet-related chronic illnesses, including hypertension, hypercholesterolemia, and diabetes mellitus, are prevalent in homeless populations and are often poorly diagnosed or inadequately treated (Davis, Weller, Jadhay, \& Holleman, 2008; Lee, Hanlon, \& David, 2005; Hwang et al., 2009; J Am Diet Assoc, 2006). Additional health risks span a wide range from experiencing unintentional injuries, physical and sexual assaults, to a wide range of foot problems (e.g., blisters, fungal infections, frostbite, and ulcers), skin problems resulting from bites due to infestations (e.g., head lice, body lice, scabies or bedbugs) and dental decay. Homeless adults have high rates of vision impairment (37\%), skin/leg/foot problems (36\%), and positive tuberculin testing (31\%) (Gelberg, Gallagher, Andersen, \& Koegel, 1997; Macnee, Hemphill, \& Letran, 1996). Though eating a nutritious diet has been shown to maintain one's health and ward off chronic disease, homelessness is understood to "preclude good nutrition" according to the National Coalition for the Homeless (National Coalition for the Homeless, 2009; J Am Diet Assoc, 2006; Oliveira \& Goldberg, 2002). Maintaining one's safety, obtaining food, and tending to other requirements to survive tend to eclipse fundamental health maintenance (Kushel, Gupta, Gee, \& Haas, 2006; Hwang, 2001; Levy \& O’Connell, 2004). With health maintenance as a secondary priority, homeless individuals are more likely to delay treatment for illnesses, and less able to take preventative measures such as eating a nutritious diet (Hwang, 2001; Levy \& O’Connell, 2004).

The issue of food insecurity further compounds the obstacles individuals who are homeless face in eating a nutritious diet. Food insecurity represents an uncertain availability to 
access nutritionally adequate and safe foods in socially appropriate ways due to limited resources. Compounding the health risks, the homeless typically lack available health care, health insurance, and the ability to engage in health maintenance behaviors. People who are homeless have described multiple barriers when trying to obtain health care including social triaging, being labeled and disrespected (Martins, 2008). Numerous studies have documented the difficulties the homeless face in trying to feed themselves. Difficulties include, being unable to purchase food, the inaccessibility of adequate cooking and food storage facilities, and being unable to access foods that meet dietary needs (Davis et al., 2008; Rodriguez, Fortman, Chee, Ng, \& Poon, 2009; Oliveira \& Goldberg, 2002; Richards \& Smith, 2006). In 2010, $14.5 \%$ of the U.S. population was labeled food insecure by the USDA (Coleman-Jensen, Nord, Andrews, \& Carlson, 2011). It is widely suggested that individuals who are homeless are at increased risk of hunger and food insecurity, although data to support such an association is limited at this time. Additionally, in a study of housing instability and food insecurity, it was reported that among individuals reporting housing instability, which is a less severe situation than homelessness, almost half (42.7\%) reported food insecurity (Kushel et al., 2006). Food insecurity is a significant predicator of negative nutritional outcomes in adults (J Am Diet Assoc, 2006; Bhattacharya, Currie, \& Haider, 2004; Holben \& Myles, 2004) and is associated with increased Body Mass Index (BMI) in adult women (J Am Diet Assoc, 2006; Bhattacharya et al., 2004; Holben \& Myles, 2004; Alaimo, 2005; Townsend, 2006). Further research shows that diets for those who are food insecure are often low in essential vitamins and minerals but high in saturated fats and cholesterol (Szerlip \& Szerlip, 2002; Oliveira \& Goldberg, 2002; J Am Diet Assoc, 2006; Bhattacharya et al., 2004; Tanumihardjo, Anderson, \& Kaufer-Horwitz, 2007). Due to a lack of financial resources, those that are food insecure consume lower cost foods that are high in 
calories, fat content, and cholesterol (Szerlip \& Szerlip, 2002; Oliveira \& Goldberg, 2002;

Tanumihardjo et al., 2007).

In addition to food insecurity, poor dietary intake is further exacerbated by the lack of kitchen facilities or opportunities for food preparation and storage. Most homeless individuals are eligible to receive benefits from the Supplemental Nutrition Assistance Program (SNAP), formerly known as the Food Stamp Program, a nutrition assistance program administered by the USDA to low-income individuals and families that provides benefits via EBT (an electronic benefits transfer) and allows participants to purchase foods at authorized retailers. Recent estimates indicated that 46 million people receive SNAP benefits each month as of June 17, 2012 (USDA Food and Nutrition Service, 2014). This program improves a household's ability to purchase more food and thereby free up income typically used for food for other purchases. One of the central tenets of SNAP is that it is intended for the purpose of purchasing non-prepared food that is lower cost and that can be prepared at home; unfortunately, homeless individuals find this program less advantageous. Homeless individuals do not have access to cooking facilities but also have limited storage facilities for non-prepared foods. As a result, individuals who are homeless may not be able to reap the nutritional advantages of SNAP to the same degree that other housed participants are able to (Richards \& Smith, 2006). 


\section{Purpose / Aim}

The purpose of this study was to learn more about homeless individuals' health and nutrition, and to test whether food insecurity and food access among homeless individuals accounts for variation in the health status of the homeless populations. The aim of the study was to examine the relationship between access to food resources, quality of food intake, level of food security; and the homeless individuals' weight, height, BMI, waist circumference, and overall health risk. A paradox seems to exist between lack of access to food in homelessness and obesity rates. The consumption of high calorie, low nutrient foods that many people experiencing homelessness consume may explain this paradox. 


\section{Method}

\section{Study Population}

To be eligible for the study, participants needed to be over the age of 18, homeless at the time of data collection, and having demonstrated mental capacity to participate in the task. Three hundred and nineteen homeless adults participated in the study. Three quarters of those interviewed reported using shelters on a daily basis in the month prior to data collection, $7.5 \%$ had not used a shelter in the past month, and $17.5 \%$ used shelters intermittently.

\section{Procedures}

Homeless individuals were recruited during the period of May 2008 to August 2010 from the community day room at Rhode Island's largest service agency for the homeless. They were offered a healthy snack as an incentive. Once a participant gave informed and written consent, an Institutional Review Board trained research assistant collected anthropometric measures, followed by a face-to-face interview. The interrater reliability of protocols was maintained at or above $90 \%$ agreement throughout the course of the assessments.

\section{Measures}

Anthropometry. Weight was determined on a calibrated scale with clothes on, height with a stadiometer and waist circumference was measure at the umbilicus underneath clothing. BMI was calculated as weight $(\mathrm{kg})$ divided by height squared $\left(\mathrm{m}^{2}\right)$. BMI is considered a reliable indicator of total body fat and used to calculate overweight (BMI of 25.0 to $29.9 \mathrm{~kg} / \mathrm{m}^{2}$ ) and obesity (BMI of $\geq 30 \mathrm{~kg} / \mathrm{m}^{2}$ ) (National Heart, Lung, and Blood Institute [NHLBI Guidelines], 1998). A BMI greater than $25 \mathrm{~kg} / \mathrm{m} 2$ (20) is associated with increased disease risk and mortality. Mortality rates increase significantly when the BMI rises above $30 \mathrm{~kg} / \mathrm{m}^{2}$. In addition, excess 
abdominal fat, as measured by waist circumference, has been established as an independent predictor of increased disease risk, particularly cardiovascular disease. According to NHLBI Guidelines, a waist circumference of over 40 inches in men and over 35 inches in women signifies increased risk in those who have a BMI of 25 to 34.9.

Food security. Food security and hunger status were assessed using the core food security module developed by the USDA (Bickel, Nord, Proce, Hamilton, \& Cook, 2000), which has been widely used and validated with low-income populations in the United States. Participants were asked the six questions on the abbreviated version and then coded as food secure, food insecure and food insecure with hunger (J Am Diet Assoc, 2006). The questions are designed to reveal the degree of food insecurity experienced in the last 12 months by highlighting specific indicators of food conditions and behaviors, such as the experience of running out of food or instances of reduced food intake (Bickel et al., 2000).

24 hour dietary recall. A twenty-four hour dietary recall was also performed by asking each participant to list all foods eaten in the previous 24 hours. Research assistants prompted for typical meal times to assist with dietary recall. A subset $(\mathrm{N}=197)$ of the sample were able to complete the dietary recall.

Demographic data. Data were assessed via interviews that queried participant's living situation and use of services. Questions were asked about how frequently the participant used a shelter, soup kitchen, and food pantry in the last month; access to a working telephone, a working vehicle, and a place to prepare a meal; and use of the Supplemental Nutrition Assistance Program.

Data Analysis. Dietary intake data were analyzed using the "Food Processor" nutrition and fitness comprehensive nutrition analysis software. Using 24 hour dietary recall, dietary 
intakes are analyzed and output displays a comparison of the client intake against recommended standards. The analysis was used to determine recommended versus actual food intake based on USDA guidelines and the Food Pyramid. Data were analyzed using the Statistical Package for the Social Sciences (SPSS) 17.0. Descriptive analyses were used to answer all aims of the study. 


\section{Results}

\section{Demographics}

Three hundred and nineteen homeless adults participated, of which 64\% $(\mathrm{n}=205)$ were male and 36\% were female. Participant age ranged from 18 years old to more than 65 years old, with the majority $(n=153)$ falling between the ages of $30-49$. More than half $(52 \%)$ of the participants lived on an income of less than $\$ 50.00$ per week, with the next largest majority (18\%) having an income of $\$ 50-\$ 200$ per week. The reported ethnic and racial background of the study population is: 47\% Non-Hispanic White, 20\% African American, 16\% Hispanic/Latino, 9\% multiracial, 5\% Native American, Asian Pacific Islander 1\%, and the remaining "other".

\section{Anthropometric data and disease risk}

Analysis of anthropometric data are reported in Table 1 and Table 2. Results indicate that almost $70 \%$ of the sample had elevated weights (BMI > 25), with $29.4 \%$ of the participants classified as overweight $(\mathrm{BMI}=25-29.9)$ and $39 \%$ obese $(\mathrm{BMI}>30)$. Twenty eight percent of the participants were of normal weight for height, and 3.8\% (N=12) were underweight. Disease risk was calculated by comparing the participant's BMI and waist circumference to norms for these two measures as indicated by the National Heart Lung and Blood Institute Guidelines (2012). The guidelines include separate cut off points for males and females relative to waist circumference, and have 4 categories of risk: increased, high, very high and extremely high (appendix A). The majority of individuals in the sample (69.6\%) were at elevated risk for disease. Specifically, 20.9\% were at increased risk for disease, $19.6 \%$ were at high risk for disease, $19.9 \%$ were at very high risk for disease, and $9.2 \%$ were at extremely high risk for disease. Only $31.6 \%$ of the sample was classified as having no increased risk. Participants' selfrating of their health indicated that a third (34.5\%) considered their health to be good, with an 
additional $24 \%$ rating their health as either very good or excellent. A little over $30 \%$ rated their health as fair, with $10 \%$ indicating that they were in poor health. 


\section{Diet}

Analysis of the twenty-four hour dietary recalls established a mean of 6.6 servings of grain per day, 2.6 servings of vegetables per day, 0.8 servings of fruit per day, 0.8 servings of dairy per day, 2.2 servings of meats and beans per day, and 17.5 servings of fats per day. In comparison to the USDA's recommendations for the number of daily servings from each food group (United States Department of Agriculture Food Guide Pyramid, 2013), the participants' intake does not meet the USDA recommendations with far fewer servings of vegetables, fruit, dairy and meats/beans than recommended and excessive servings of fats (see chart) (United States Department of Agriculture [USDA], 2005). 


\section{Food security}

Of the 252 participants for whom complete Food Security Survey data were available, only $6 \%$ were food secure. Of the $94 \%$ food insecure individuals, $30 \%$ were classified as having low food security and sixty-four percent were classified as very low food security (formerly food insecurity with hunger). Given the high rates of food insecurity among the entire sample, there was very little association between food security status and health indicators: weight, waist circumference, disease risk or obesity. There was a suggestive trend $(p=.06)$ that individuals who were food insecure had slightly higher BMI than those who were food secure $(\mathrm{F}=3.351$, $\mathrm{p}<.07)$.

\section{Supplemental Nutrition Assistance Program (SNAP)}

Over half of the sample $(55 \% ; \mathrm{N}=160)$ were currently receiving SNAP benefits, with $79 \%$ reporting having been utilizing SNAP benefits at one time and $69 \%$ having been utilizing SNAP benefits sometime in the last 12 months.

\section{Utilization of Pantry and Soup Kitchen}

During the past month, more than half (59\%) had eaten a daily meal in a soup kitchen with $18 \%(\mathrm{n}=55)$ reporting eating no meals in a soup kitchen during the past month. Almost $70 \%$ of respondents had not used a food pantry in the past month, with $11 \%$ using it only once. Individuals classified as obese were significantly more likely to report having eaten in a soup kitchen during the past month than non-obese individuals (Chi Square 3.57, $\mathrm{p}=0.05$ ). 


\section{Discussion and Implications}

The findings from this study reveal important information about the health and nutrition status of a homeless population in the greater Providence area. Most notably, an overwhelming majority of the individuals surveyed were overweight or obese. A recently completed study on obesity among the homeless reported rates of $33 \%$ obesity, similar to rates of non-homeless adult populations (Zimmerman, 2012). In the data reported here, the prevalence of excess weight in the study population is related to a very high level of disease risk, and this finding is in accordance with the high rates of chronic disease seen in the general homeless population (Rodriguez et al., 2009). The population's diet was exceptionally heavy in fat, and had considerably fewer servings than recommended from other food groups. These findings of poor diet quality are consistent with other studies about the diet of homeless individuals (Davis et al., 2008; Lee et al., 2005; Szerlip \& Szerlip, 2002). The findings of poor diet quality and high rates of obesity must be understood in the context of the other major finding: the majority of the study population is food insecure with hunger.

It is interesting to note that very few significant findings were reported between food insecurity status, obesity and dietary intake. We attribute this lack of statistical association to the excessively high rates of obesity and food insecurity. The data collection was completed on people experiencing homelessness who were predominantly food insecure. This population often depends on soup kitchens and consumes low nutrient, high fat food, explaining higher obesity rates. A food secure comparator group was unavailable, leading to lack of variability in the study sample. Statistical association relies in part on variability. As such, it is difficult to make inferences about these associations. Despite such high rates of food insecurity and obesity, the cross sectional nature of the data impedes our ability to examine the direction of effects. It would 
be interesting to examine whether these high rates of obesity and food insecurity predate the onset of homelessness and the degree to which ongoing homelessness exacerbates the increased risk of disease. Dietary recall bias in this cross-sectional study population may also skew the data from showing statistical significance. It is not hard to imagine a confluence of factors - low income, poor job opportunities, mental and physical illness coming together to contribute to the complex configuration of homelessness.

The findings from this study also highlight the challenges facing the homeless as they try to feed themselves. Among low income populations, coping strategies adopted to avoid hunger include visits to soup kitchens and food pantries and utilization of SNAP benefits. For the majority of this homeless population, however, soup kitchens were the predominant source of food. Not surprisingly, far fewer homeless individuals reported using a food pantry. Since homeless individuals typically have limited to no availability of food storage or preparation, the resources provided by pantries have limited utility. Of particular concern here is the relatively low participation in SNAP (roughly 55\%) when it is likely that close to $100 \%$ of the individuals surveyed would have been SNAP eligible. While SNAP participation would surely increase access to benefits to purchase food, data from focus groups among a similar population (Gorman, Horton, \& Houser, 2006) highlight the barriers perceived by homeless individuals to using EBT.

\section{Public Health Policy Implications}

Public health policies at both the state and federal levels have focused on numerous initiatives to improve the nutrition and health of all, with particular emphasis on the needs of low-income individuals and families. In fact, a number of initiatives, including partnerships between local emergency food relief organizations and the agricultural community to bolster the amount of fruits, vegetables and dairy products available for consumption are being undertaken. 
Additionally, many pantries have incorporated nutrition education programs into their work in the hopes of empowering individuals and families to improve their nutritional intakes when shopping on limited resources. Nonetheless, most of these efforts fall beyond the reach of homeless individuals who continue to be unable to store and prepare foods and as such are much less likely to shop with EBT.

As we consider efforts to improve the nutritional quality of homeless individuals, SNAP seems to be an important opportunity. At the same time, the underutilization of SNAP among homeless populations has been identified as a key contributor to food insecurity. While SNAP regulations in general do not allow for the purchase of hot, prepared foods, the Food \& Nutrition Service of the USDA, which administers SNAP allows states to adopt the Restaurant Meals Program for certain SNAP recipients. In Rhode Island, advocates have formed a partnership with the Department of Human Services to develop the RMP specifically for homeless, older adult and disabled SNAP households. The program was launched in October of 2011, in 5 restaurants all located in and around the city of Providence. While the evaluation of this initiative is only just beginning to yield any data, the program has been positively received and participation by the older adult, disabled, and homeless has increased with each month of participation. Outreach efforts have been targeted to both SNAP clients and service providers working with the target population in order to provide accurate information and increase access to the program. In ongoing discussion of a statewide program expansion, both state human service administrators as well as advocates hope to be able to evaluate the program's effectiveness and target both restaurants and potential client base that will provide the greatest nutrition and health benefit to the target populations while increasing overall access to food. 
A multifaceted, creative approach to address food accessibility in the homeless population is key to achieving more efficiency in the health care system. The goals of Healthy People 2020, a set of goals and objectives with 10-year targets designed to guide national health promotion and disease prevention, recognize that resources such as safe housing and access to local food are barriers to good health among low-income populations (HealthyPeople.Gov, 2014). Improving the health and well-being of the homeless will require increased access to nutrition, so as to decrease the numbers of overweight and obese individuals and thereby lower overall disease burden and health care costs. Healthy People 2020 supports efforts to change individuals' behaviors and it also addresses the policies and environments that support these behavior changes. 


\section{Conclusions}

In conclusion, there is a paradox between lack of access to food in homelessness, obesity rates and dietary intake. This brings to light the consumption of high calorie low nutrient foods that many people experiencing homelessness consume. Access to nutritional foods needs to be improved for homeless individuals. Currently, SNAP benefits and food pantries are not of maximum utility in improving the nutrition of individuals who are homeless due to lack of an area to store and prepare the obtained foods. Studies comparing the health status of food insecure homeless individuals with the health status of food secure homeless individuals would provide useful information to this area of research, although a food secure sample may not be feasible to obtain. There are promising programs beginning to offer prepared meals to homeless individuals through SNAP. A continuous multi-faceted approach is necessary to overcome the obstacles homeless individuals face in obtaining nutritious food and maintaining healthy weights. An approach that can achieve such goals will decrease acute and chronic illness among homeless individuals and display a long-term decrease in health-care dollars spent on this growing population. 


\section{Acknowledgements}

This research was funded in part by a grant from the Rhode Island Foundation, the University of Rhode Island Presidents Partnership on Food, Hunger and Nutrition, and the Rhode Island Area Health Education Center. The pilot study for this work was originally presented at American Public Health Association, in Boston, MA, November 2006. The final research was presented at the American Public Health Association Annual Meeting, in Boston, MA, November 2013. 


\section{References}

Alaimo, K. (2005). Food security in the United States: An overview. Top Clin Nutr, 20(4), 281298.

Bhattacharya, J., Currie, J., \& Haider, S. (2004). Poverty, food insecurity, and nutritional outcomes in children and adults. Journal of Health Economics, 23(4), 839-62.

Bickel, G., Nord, M., Proce, C., Hamilton, W., \& Cook, J. (2000). Guide to measuring household food security [U.S. Department of Agriculture]. Retrieved from USDA: http://www.fns.usda.gov/fsec/files/fsguide.pdf

Cheung, A. M., \& Hwang, S. W. (2004). Risk of death among homeless women: a cohort study and review of the literature. Canadian Medical Association Journal, 170(8), 1243-7.

Coleman-Jensen, A., Nord, M., Andrews, M., \& Carlson, S. (2011). Household food security in the United States in 2010 (ERR-125). Washington, DC: Government Printing Office.

Davis, L. R., Weller, N. F., Jadhay, M., \& Holleman, W. L. (2008). Dietary intake of homeless women residing at a transitional living center. Journal Health Care Poor Underserved, 19(3), 952-62.

Dinour LM, Bergen D, Yeh MC. (2007). The food insecurity-obesity paradox: a review of the literature and the role food stamps may play. J Am Diet Assoc, 107(11), 1952-61.

$\mathrm{Nu}$ Connexions, (n.d.). Esha's food processor nutrition analysis and fitness software . Retrieved from http://www.nuconnexions.com/Software/FoodProcessor.htm

Gelberg, L., Gallagher, T. C., Andersen, R. M., \& Koegel, P. (1997). Competing priorities as a barrier to medical care among homeless adults in Los Angeles. American Journal of Public Health, 87(2), 217-20. 
Gorman, K. S., Horton, K. D., \& Houser, R. F. (2006). Food security, hunger, and food stamp participation among low-income working families in Rhode Island. Journal of Hunger \& EnVironmental Nutrition, 1(1), 105-25.

HealthyPeople.gov (August 5, 2014). About healthy people. Retrieved from http://www.healthypeople.gov/2020/about/default.aspx

Holben, D. H., \& Myles, W. (2004, March). Food insecurity in the United States: Its effects on our patients. Am Fam Physician, 69(5), 1058-1064. Retrieved from http://www.aafp.org/afp/2004/0301/p1058.html

Hwang, S.W. (2001, January 23). Homelessness and Health. Canadian Medical Association Journal, 164(2), 229-33.

Hwang S.W., Bugeja A.L. (2000, July 25). Barriers to appropriate diabetes management among homeless people in Toronto. Canadian Medical Association Journal, 163(2), 161-5.

Hwang, S. W., Wilkins, R., Tjepkema, M., O’Campo, P. J., \& Dunn, J. R. (2009, October 26). Mortality among residents of shelters, rooming houses and hotels in Canada: An 11-year follow-up study. BMJ, 339:b4036.

Kirlin, J.A. (2012,). Supplemental Nutrition Assistance Program. United States Department of Agriculture Economic Research Service. Retrieved from: http://www.ers.usda.gov/Briefing/SNAP/.

Kushel, M. B., Gupta, R., Gee, L., \& Haas, J. S. (2006). Housing instability and food insecurity as barriers to health care among low-income Americans. Journal of General Internal Medicine, 21(1), 71-77.

Lee, T. C., Hanlon, J. G., \& David, B. J. (2005). Risk factors for cardiovascular disease in homeless adults. Circulation, 111(20), 2629-35. 
Levy, B. D., \& O’Connell, J. J. (2004). Health care for homeless persons. New England Journal of Medicine, 350(23), 2329-2332.

Macnee, C., Hemphill, J., \& Letran, J. (1996). Screening clinics for the homeless: Evaluating outcomes. J Community Health Nurs, 13(3), 167-77. Retrieved from http://www.jstor.org/stable/3427764

Martins, D. C. (2008). Experiences of homeless people in the healthcare delivery system: A descriptive phenomenological study. Public Health Nurs, 25(5), 420-30.

The McKinney-Vento Homeless Assistance Act, U.S. Const. art. XLII, § 11302, (1989)National Coalition for the Homeless. (2009). Fact sheet: Health care and homelessness. Retrieved from http://www.nationalhomeless.org/factsheets/health.html

National Heart, Lung, and Blood Institute. Guidelines on overweight and obesity: National Institutes for Health. (1998). Guidelines on overweight and obesity. Retrieved from http://www.nhlbi.nih.gov/health/public/heart/obesity/lose_wt/bmi_dis.htm

Nord, M. (2008). Food insecurity in the United States: definitions of hunger and food security. United States Department of Agriculture Economic Research Service. Retrieved from http://www.ers.usda.gov/Briefing/FoodSecurity/labels.htm

Oliveira, N. L., \& Goldberg, J. P. (2002). The nutrition status of women and children who are homeless. Nutr Today, 37(2), 70-77.

Position of the American Dietetic Association: Food insecurity and hunger in the United States. [Special issue]. (2006). J Am Diet Assoc, 106(3) http://dx.doi.org/10.1016/j.jada.2006.01.016

Richards, R., \& Smith, C. (2006). The impact of homeless shelters on food access and choice among homeless families in Minnesota. J Nutr Educ Behav, 38(2), 96-105. 
Rodriguez, R. M., Fortman, J., Chee, C., Ng, V., \& Poon, D. (2009). Food, shelter and safety needs motivating homeless persons' visits to an urban emergency department. Ann Emerg Med, 53(5), 598-602.

Schanzer, B., Dominguez, B., Shrout, P. E., \& Caton, C. L. (2007). Homelessness, health status, and health care use. Am J Public Health, 97(3), 464-9.

Szerlip, M. I., \& Szerlip, H. M. (2002). Identification of cardiovascular risk factors in homeless adults. Am J Med Sci, 324(5), 243-6.

Tanumihardjo, S. A., Anderson, C., \& Kaufer-Horwitz, M. (2007). Poverty, obesity, and malnutrition: An international perspective recognizing the paradox. J Am Diet Assoc, 107(11), 1966-72.

Townsend, M. S. (2006). Obesity in low-income communities: Prevalence, effects, a place to begin. J Am Diet Assoc, 106(1), 34-7.

Turnbull, J., Muckle, W., \& Masters, C. (2007). Poverty and human development: homelessness and health. CMAJ, 177(9), 1065-66. http://dx.doi.org/10.1503/cmaj.071294

United States Conference of Mayors. (2011). A status report on hunger and homelessness in America's cities. Washington, DC: Government Printing Office.

United States Department of Agriculture. (2005). Sample of USDA food guide and the DASH eating plan at the 2,000-calorie level. Dietary guidelines for Americans, 2005. Retrieved from http://www.heatlh.gov/dietaryguidelines/dga2005/document/default.htm

United States Department of Agriculture. (2013). Food Guide Pyramid. Retrieved from http://www.cnpp.usda.gov/fgp.htm 
United States Department of Agriculture. (2014). Supplemental nutrition assistance program $(S N A P)$. Retrieved from http://www.fns.usda.gov/snap/supplemental-nutrition-assistanceprogram-snap

Zimmerman, R. (May 22, 2012). Study suggests one-third of homeless in U.S. are obese. Retrieved from http://commonhealth.wbur.org/2012/05/homeless-obese 


\section{Table 1.}

Anthropometric Measures $(N=313)$

\begin{tabular}{lllc}
\hline & Number & Mean & $\begin{array}{c}\text { Standard } \\
\text { Deviation }\end{array}$ \\
\hline Weight & 311 & 186.37 & 51.36 \\
$\quad$ Males & 200 & 189.81 & 50.64 \\
Females & 111 & 180.17 & 52.28 \\
Height & 313 & 67.09 & 4.06 \\
$\quad$ Males & & 68.9 & \\
Females & & 63.9 & \\
BMI & 308 & 29.48 & 7.79 \\
Males & & 28 & \\
Females & & 31 & \\
Waist Circumference & 303 & 38.40 & 6.93 \\
$\quad$ Males & & 38.2 & \\
Females & & 38.7 & \\
& & & \\
\hline
\end{tabular}


Table 2.

Weight Classification by Gender $(n=313)$

\begin{tabular}{lcc}
\hline & $\mathrm{N}$ & $\%$ \\
\hline Underweight & 1 & 3.8 \\
Normal & 2 & \\
$($ BMI 18.5-24.9) & 8 & 27.8 \\
Overweight & 7 & \\
$($ BMI 25-29.9) & 9 & 2.8 \\
Obese & 2 & \\
(BMI 30-39.9) & 9 & 29.4 \\
Extreme $($ BMI >=40) & 4 & \\
& 2 & 8.8 \\
\hline
\end{tabular}


Table 3.

Title Dietary Intake by Food Group for Study Participants

\begin{tabular}{lll}
\hline Food Group & $\begin{array}{l}\text { USDA recommended number of } \\
\text { daily servings (USDA, 2005) }\end{array}$ & $\begin{array}{l}\text { Daily mean number of servings } \\
\text { for study participants }\end{array}$ \\
\hline Grains & 6 oz equivalents = 6 servings & 7.9 servings \\
Vegetables & 2.5 cups $=5$ servings & 2.8 servings \\
Fruits & 2 cups $=4$ servings & 1.3 servings \\
Dairy (milk group) & 3 cups $=3$ servings & 1.1 servings \\
Meat and beans & 5.5 oz equivalents = 5.5 servings & 2.2 servings \\
Fats ${ }^{1}$ & 6 teaspoons of oils = 6 servings & 74.0 servings \\
\hline
\end{tabular}

1 Please note: the current Dietary Guidelines for Americans provides separate categories for plant/nut oils and fats, with the latter falling into the category of "Discretionary Calorie Allowance" (USDA, 2005). For the purposes of this study, because the specific types of fats and oils consumed were unable to be determined; one general "Fats" group was utilized. It should be mentioned, however, plant and nut oils are considered a "healthy" food group because they are a major source of vitamin E and essential fatty acids (34). It is the plant and nuts oils that are referred to in the above USDA recommended servings. 


\section{Appendix A}

\section{Table A1}

Classification of Overweight and Obesity by BMI, Waist Circumference, and Associated Disease Risks

Disease Risk* Relative to Normal Weight \& Waist Circumference

\begin{tabular}{|c|c|c|c|c|}
\hline & $\begin{array}{c}\text { BMI } \\
\left(\mathrm{kg} / \mathrm{m}^{2}\right)\end{array}$ & $\begin{array}{l}\text { Obesity } \\
\text { Class }\end{array}$ & $\begin{array}{l}\text { Men } 102 \mathrm{~cm}(40 \text { in) or less } \\
\text { Women } 88 \mathrm{~cm}(35 \mathrm{in}) \text { or less }\end{array}$ & $\begin{array}{c}\text { Men }>102 \mathrm{~cm}(40 \mathrm{in}) \\
\text { Women }>88 \mathrm{~cm}(35 \mathrm{in})\end{array}$ \\
\hline Underweight & $<18.5$ & & - & - \\
\hline Normal & $18.5-24.9$ & & - & - \\
\hline Overweight & $25.0-29.9$ & & Increased & High \\
\hline \multirow[t]{2}{*}{ Obesity } & $30.0-34.9$ & I & High & Very High \\
\hline & $35.0-39.9$ & II & Very High & Very High \\
\hline Extreme Obesity & $40.0+$ & III & Extremely High & Extremely High \\
\hline
\end{tabular}

